\title{
Effects of Model Age on Adult Female Consumers' Purchase Intentions and Attitudes for an Age-Specific Product, Clothing
}

\author{
Joy M. Kozar \\ Department of Apparel, Textiles, and Interior Design, Kansas State University \\ 320 Justin Hall, Manhattan, KS 66506-1405, USA \\ Tel: 1-785-532-1394Ｅ-mail: jkozar@ksu.edu
}

Received: January 20, 2012 Accepted: February 16, $2012 \quad$ Published: April 1, 2012

doi:10.5539/ijms.v4n2p22 URL: http://dx.doi.org/10.5539/ijms.v4n2p22

This research was supported by the Office of Research and Sponsored Programs, the Center on Aging, and the College of Human Ecology, Kansas State University, Manhattan, KS, USA.

\begin{abstract}
The purpose of this study was to examine the effect of model age on female consumers' purchase intentions and attitudes for an age-specific product such as clothing. The sample for this study consisted of 377 women between the ages of 30-80. The instrument designed for this study included four major scales to assess participants' beliefs about fashion models depicted in clothing advertisements, participants' purchase intentions of the clothing worn by the models in the advertisements, participants' perceived similarity to the models shown in the ads, and participants' perceived fashionability of the clothing worn by the models. The stimuli used in this study included four full-colored photographs of current fashion models. Findings revealed that participants preferred older models over younger models, with consumers exhibiting greater purchase intent of clothing appearing on older models. Moreover, perceived similarity was found to be a significant predictor of participants' perspectives of the models, in terms of appearance and attractiveness, fashionability, and purchase intentions.
\end{abstract}

Keywords: Apparel purchasing behavior, Baby Boomers, Fashion advertisements, Generation X, Social comparison

\section{Review of Literature}

Today's apparel retailers are faced with a variety of challenges in the marketplace, including a lack of interest and spending among consumers, fierce competition, and a sluggish economy. Recent reports cite the impact of the prolonged recession coupled with slow consumer spending and an over-saturated market on retail sales (Berk, 2009; Linn, 2008). During a period of six consecutive months in 2008, overall retail sales fell, culminating with the 2008 holiday season characterized as "one of the worst" in decades (Moin, 2008). Department stores and apparel specialty retailers are among those firms struggling most to compete (Rosenbloom, 2009). Consumer spending accounts for $70 \%$ of total economic activity; a drop in retail sales in May and June of 2010 "raised fears that the economy could be in danger of slipping back into recession" ("Department store sales," 2010). During the 2008 holiday season, sales for women's apparel, men's apparel, and footwear declined $22.7 \%, 14.3 \%$, and 13.5\%, respectively (Moin, 2008). During the 2010 holiday season, a 5.5\% sales increase among U.S. apparel retailers was recorded (Timberlake, 2008). Nonetheless, Horyn (2009) describes the current business climate for designer fashion labels as "the chilliest... in years" (n.p.).

Retailers also continue to cut back on inventory and close stores; in March 2009, retailers slashed inventories for the seventh straight month, the longest stretch since 2002 . Sales at specialty clothing retailers fell $0.5 \%$ in March 2009, while department and general merchandise stores reported a 0.1\% drop ("Retail Sales Fall," 2009). In a national study of over 5,000 American consumers, participants noted reduced overall spending for numerous product categories, including purchases for new apparel goods and accessory items (“Americans expect," 2009).

In response to the current economic and marketplace conditions, it is evident that retailers must identify strategies or methods to re-stimulate consumer spending and drive sales. A multitude of literature noting apparel retailers' general zeal for teenage and young adult consumers exists, while an overall disinterest in other 
consumer groups is typical. Yet, it is these "other" consumer groups, including Generation X and Baby Boomers, that have greater spending power and aren't nearly as capricious as younger target markets (O'Donnell, Petrecca, \& Butrymowicz, 2008; WGSN, 2007). According to a report published by CNBC (“American boomers," 2006), targeting Baby Boomers is a lucrative strategy for invigorating consumer interest, particularly when considering the \$2 trillion spending power of Boomers. As reported by Florin, Callen, Mullen, and Kropp (2007), Baby Boomers have acquired greater sums of wealth and have more spending power than any other cohort in history.

Generation X consumers have been found to outspend Baby Boomers for luxury goods by as much as $6.3 \%$. In a previous report on the Generation X market segment, the significant spending power of Gen Xers was noted, with a persuasion to marketers to attune to the spending habits and desires of this cohort more effectively. This is particularly significant to the personal luxuries industries, including fashion, accessories, and cosmetics ("Gen $X, " 2006)$. Overall, Generation X has an estimated $\$ 736$ billion in spending power ("RAB," 2005).

Recently published reports show, however, that women outside the 20 -something-age-range feel underserved in the marketplace, especially by apparel retailers. In a 2008 USA Today article, female consumers reported feeling ignored by apparel retailers - nearly half of 1,600 women between the ages of 35 to 74 participating in the survey reportedly felt "left out" in the marketplace (O'Donnell et al., 2008). This is despite the fact that today's women are found to continue to choose more fashion-forward brands in middle and older ages. Recently launched websites such as faboverfifty.com and The Fashionista Report are also gaining popularity with female consumers 50 and older, offering tips on beauty, wellness, nutrition, lifestyle, and fashion (Rohan, 2009). Yet, as reported by Rohan (2009), apparel retailers still fail to capitalize on the economic significance and purchasing power of Baby Boomers. As compared to other market segments, Baby Boomers are found to spend 13\% more on women's apparel and 11\% more on men's apparel (WGSN, 2007).

Older adults are typically not used as models and spokespersons in ads featured in mainstream media (Carrigan \& Szmigin, 2000). Simcock and Sudbury (2006) reported that older adults, particularly older women, are under-represented in the media and general consumer advertising, particularly in cosmetic, beauty, fashion and clothing advertisements. Older models are typically used for a limited range of goods and services, including those related to health care (i.e., to overcome disabilities and infirmity) and finance (Carrigan \& Szmigin, 2000; Szmigin \& Carrigan, 2000). Consumers in one study noted the demoralizing nature in which older adults are depicted in advertisements and felt that advertising executives perceived that all adults 50 and over were disabled in some way - thus, older models were not suitable for ads for products such as clothing, jewelry, cosmetics, and automobiles (Carrigan \& Szmigin, 2000).

Chowdhary (2000) reported that apparel retailers should be more mindful when selecting promotional strategies for fashion apparel goods to middle-age and older consumer groups. Florin et al. (2007) also emanated consumers' preference for more personalized marketing strategies; in a series of reports published by WGSN in 2007, it was noted that Baby Boomers do not want to be marketed or advertised to as if they comprise a younger market segment. Further research exploring appropriate strategies for enticing these market segments is clearly warranted.

Szmigin and Carrigan (2000) noted that older models should be more readily depicted in advertisements to accurately represent the make-up of today's society. The authors recognized that it is important for advertisers to consider how they are communicating with older consumers through the frequency and representation of older and younger models. The authors suggested that advertisers may be misled in assuming that older consumers are not persuaded by the age of the model or spokesperson; in other words, "Some advertisers may wrongly believe that older people do not like to see models of a similar age to themselves in advertisements" (p. 129). In fact, through their research, the authors found that advertisers tend to believe (albeit wrongly) that consumers aged 50 and older preferred younger models. Responses from participants (advertising executives) often reflected the following comment, “...we all know younger people look better, are more fun and attractive and so make better models in advertising" (p. 232).

Currently, little research exists exploring the effect of model age on consumers' purchase intentions, particularly for an age-specific product such as clothing. In a study by Greco, Swayne, and Johnson (1997), the researchers examined the relationship between model age and consumer behavior for an age-neutral product, coffee. As a result of their analyses, while participants did tend to favor models representing their approximate age groups, the researchers found that model age did not have a significant effect on consumers' purchase behavior. However, in purchases for an age specific product such as clothing, previous research has shown that marketers should consider the age of the model in creating effective advertising campaigns. According to Kozar and Damhorst (2008), participants aged 60 to 80 had more favorable ratings of apparel advertising models more 
closely resembling their age. Participants perceived older models as more attractive than younger-age fashion models and indicated a stronger likelihood of purchasing clothing worn by older models.

Studies have suggested that advertising executives are apprehensive about using older models for fear that younger audiences might be alienated; findings which have not been proven (Carrigan \& Szmigin, 2000; Szmigin \& Carrigan, 2000). In fact, Greco et al. (1997) provided evidence to suggest that older models are oftentimes viewed positively by younger consumer groups. These results are reflected in the following discussion.

Utilizing the concept of perceived similarity is helpful in understanding age effects on consumers' attitudes towards ads and purchase intention. According to Festinger (1954), individuals are typically less impacted by others who are too different or divergent from one's own characteristics. Characteristics used in forming these impressions are usually superficial, such as dress and appearance (Steinhaus \& Lapitsky, 1986). Oftentimes, consumers have more positive responses to those perceived as similar. Simons, Berkowitz, and Moyer (1970) noted that perceived similarity impacts interpersonal attraction which is found to enhance the communication (effectiveness) of the ad. Interestingly, in one study, younger consumers perceived to be similar to both younger and older models, with the same social attraction to either age model, and evaluated the younger models as less trustworthy as compared to the other models. Conversely, older consumers only perceived similarity to older models and were significantly less socially attracted to younger models as compared to older models. The older consumers also rated the younger models as being significantly less trustworthy and credible (Steinhaus \& Lapitsky, 1986).

The current study utilizes a sample of women ranging in age from 30 to 80 to examine the effect of model age on female consumers' purchase intentions and attitudes for an age-specific product such as clothing. Objectives of this study include an assessment of the following:

(1) What is the effect of model age on: (a) participants' attitudes or beliefs about the model; (b) participants' intentions to purchase the clothing worn by the model; (c) participants' perceived similarity to the model; (d) participants' perceived fashionability of the model's clothing?

(2) What is the relationship between participants' perceived similarity to the models and their: (a) perceptions' of the models' appearances and attractiveness; (b) purchase intentions; (c) perceptions' of fashionability?

\section{Method}

\subsection{Sample}

As noted above, the sample for this study included women between the ages of 30 and 80 . Using the stages of the human life cycle (Levinson, 1996), the age range of participants included either those transitioning into, or currently in, the middle or older adulthood life stages. Participants were recruited from two states in the Midwestern and Southern regions of the United States through various philanthropic, social, and professional organizations. A pretest of the stimuli and questionnaire was conducted with a focus group of women comprising this age group. Utilizing a quantitative approach, the instrument was tested using four primary scales to assess participants' beliefs about the models' appearances and attractiveness, participants' purchase intentions and perceived similarity to the models in the ads, and perceived fashionability of the model's clothing. Utilizing a repeated measures format, pretest participants were asked to evaluate four different photographs of female fashion models on the constructs of each scale. This tactic was useful in determining whether perceived ages of the stimuli were perceptible.

\subsection{Stimuli}

Stimuli used in the final study included four full-color photographs depicting female fashion models appearing of varying adult ages. The photographs were originally selected from advertisements in various fashion magazines and apparel catalogs. Modifications were made to each of the images by a trained photographer. Specifically, to decrease the apparent age of each model, alterations were made including erasing and/or softening wrinkles around the models' eyes, mouths, necks, and hands, and changing the models' hair colors. This created two age versions of each model. Of particular note, the clothing worn by each of the models was not modified. Due to model and photographer rights, the pictures of the models could not be reprinted.

\subsection{Instrument}

Questions pertaining to participants' demographic characteristics were included in the survey instrument. The questionnaire also incorporated four primary scales, including items measuring participants' beliefs about the models' appearances and attractiveness, participants' purchase intentions, participants' perceived similarity to 
the models, and participants' perceived fashionability of the model's clothing. As part of the current study, participants were asked to rate the stimuli on five different items using a 7-point semantic differential scale: Boring/Interesting, Unappealing/Appealing, Unimpressive/Impressive, Unattractive/Attractive, and Not Eye Catching/Eye Catching. This measure was adopted from that previously developed and tested by Petroshius and Crocker (1989) to assess spokesperson characteristics on advertisement and product evaluations.

Intended purchase behavior is a method oftentimes used to assess the effectiveness of an ad (Steinhaus \& Lapitsky, 1986). As part of this study, participants' intentions to purchase the clothing worn by the models in the photographs were evaluated. Questions pertaining to participants' purchase intentions that included three bipolar adjective choices: Unlikely/Very Likely, Improbable/Very Probable, and Impossible/Very Possible were used (Kim, 1995).

A 5-point ordered set of options ranging from 1 (Strongly Disagree) to 5 (Strongly Agree) was used to evaluate how similar participants felt to the models in the photographs on five characteristics, including overall lifestyle, dress, appearance, attractiveness, and body shape (Appiah, 2001; Posavac \& Posavac, 2002; Whittler, 1989). Additionally, to measure perceived fashionability of the model's clothing, participants rated the models' clothing on four adjectives: fashionable, current, attractive, and up-to-date (Clayton, Lennon, \& Larkin, 1987).

To confirm that participants perceived a significant age difference between the younger and older versions of each model, respondents were asked to indicate which age group, in 10-year increments from 20-29 to 70-79, they estimated the model to belong to. Significant mean age differences between the younger and older versions of each model were then tested before assessing the differences in ratings between the older and younger versions of each model on the four primary constructs described above.

\subsection{Procedure}

Each participant was given a folder which contained a questionnaire and one photograph of a model. Participants were allowed to view only one model to eliminate influence of comparisons and to reduce participant fatigue. Participants were instructed to individually complete the questionnaire while referring to the photograph.

\subsection{Data Analysis}

Descriptive statistics were analyzed on the demographic variables included in the questionnaire. To evaluate the reliability of the multiple item measures, Cronbach's standardized alpha was used (Krathwohl, 1998). Independent sample $t$-tests evaluated the effectiveness of the age treatments applied to each model. The data were then split to organize the output by group (model number and age version). This allowed data regarding participants' beliefs about the models, purchase intentions, perceived similarity and fashionability to be examined for both the younger and older versions of each model. Analysis of variance (ANOVA) between-subjects effects was used to analyze the effects of the age treatments on the four summed variables. To examine the relationship between perceived similarity and the other three summed variables, simple linear regression analyses were used.

\section{Findings}

\subsection{Overview of Sample}

A total of 377 women ranging between the ages of 30 to 80 participated in the study. The mean chronological age of participants was 58.5. As seen in Table I, a higher proportion of women in their $50 \mathrm{~s}, 60 \mathrm{~s}$, and $70 \mathrm{~s}$ participated in the study as compared to those in their $30 \mathrm{~s}$ and $40 \mathrm{~s}$. The majority of the sample $(83 \%)$ was European American, with the remaining participants belonging to African American (11.5\%) or other ethnic groups (5.5\%). Approximately 70 percent of the sample reported graduating from college, with the mean household income reported by participants as ranging from $\$ 35,000-49,999$.

\subsection{Reliability of Measures}

Cronbach's standardized alpha was used to assess the reliability of measures. Based on this analysis, all coefficient estimates for the constructs were found acceptable (Krathwohl, 1998). The standardized alpha for the beliefs about the models scale and purchase intentions scale were .93 and .94 , respectively. The reliabilities of the perceived similarity and perceived fashionability scales were found to be .83 and .86 . To provide further support for creating the summed variables used in this study, the residuals of the computed scores were also examined. In this test for normality, a relatively straight line relationship among the points existed.

\subsection{Stimuli Age Treatment Effects}

Using a two-way ANOVA with assigned model number (Model 1, 2, 3 or 4) and model age (older vs. younger) representing the factors, it was found that participants perceived a significant age difference between the older 
and younger versions of all four stimulus models. Based on participants' responses, the older versions of three of the four models were perceived to be 50-59 years of age, with the older version of the fourth model (Model 2) perceived to be 60-69 years old (Table II). Among the younger versions of the models, three of the four stimulus models were rated by participants as being 30-39 years of age; the younger version of the fourth model (Model 2) was perceived to be 40-49 years old. A frequency analysis also revealed that the distribution of respondents viewing the older and younger versions of each model was fairly equal. Specifically, 172 participants viewed the older versions of the stimulus models; 162 participants viewed the younger versions of the models.

Univariate ANOVA assessed the significance of the age treatment effects on participants' beliefs about the models' appearances and attractiveness, purchase intentions, and perceived fashionability of the model's clothing. As a result, age treatments were found to be significantly related to attitudes towards the models $(F=$ 15.71, $d f=1,347, p<.0001)$ and purchase intentions $(F=12.44, d f=1,349, p<.0001)$. Mean scores showed that participants preferred the older models $(M=5.47)$ over the younger models $(M=4.90)$; as well, the older models elicited greater purchase intentions among the participants $(M=4.11)$, as compared to the younger models $(M=3.37)$.

In exploring Objective 2, simple linear regression analyses were used to assess the relationship between perceived similarity and the other three summed variables. As a result, perceived similarity was shown to be a significant predictor of participants' attitudes toward the ad $(F=44.35, d f=1,345, p<.0001)$, purchase intentions $(F=118.51, d f=1,347, p<.0001)$, and perceived fashionability of the model's clothing $(F=44.6, d f$ $=1,351, p<.0001)$. Participants who perceived more similarity to the models in terms of lifestyle, dress, appearance, values, attractiveness, and body shape, held more favorable opinions about the models' appearances and attractiveness. Participants who perceived more similarity to the models also indicated a greater likelihood of purchasing the model's clothing and perceived the model's clothing as being current, up-to-date, and stylish.

\section{Discussion}

The results of this study indicate that model age may have an effect on female consumers' purchase decisions and attitudes for an age-specific product such as clothing. Participants in this study ranged in age from 30 to 80 , with a higher proportion of participants between the ages of 50-80. Findings showed that older models (or those perceived to be within the same age range as the majority of the sample) had a significantly greater impact on participants' purchase intentions as compared to models perceived to be younger in age. That is, participants indicated a stronger likelihood of purchasing the clothing worn by the older models, even though the clothing shown on both the older and younger versions of each model was not manipulated. Moreover, participants held more favorable beliefs about the older models' appearances and attractiveness as compared to the younger models.

These findings are similar to those previously reported (Kozar \& Damhorst, 2008; Steinhaus \& Lapitsky, 1986). As part of the Kozar and Damhorst study, women between the ages of 60-80 indicated a stronger likelihood of purchasing clothing from retailers who use older models in their advertising. Similarly, Steinhaus and Lapitsky (1986) found that older women perceived older models as more believable, qualified, and credible when assessing fashion apparel. In the current study, perceived similarity also impacted participants' perceptions of the model's attractiveness and fashionability, and indicated a stronger purchasing intent when models were perceived as being similar.

The implications of these findings are relevant to industry professionals. In targeting female consumers for an age-specific product such as clothing, particularly Baby Boom consumers, there is strong evidence to suggest that marketers and retailers should consider the age of the model used in their advertising materials. Clearly, it is conceivable that adult female consumers may have a preference for fashion models perceived to more closely represent their actual age groups. In an era of stagnant sales for women's apparel and considerable competition among retailers, strategies that can be implemented to stimulate purchase behavior and foster customer loyalty should be considered.

The findings of this study also relate to those reported by Szmigin and Carrigan (2000). As part of their research, advertising executives responded that it is only acceptable to use older female models when the models "do not actually look old" (p. 232). In this study, participants rated the older models as being more appealing and attractive; that is, those models perceived to be between the ages of 50-59 and 60-69 were viewed more favorably than those appearing to be in their $30 \mathrm{~s}$ and $40 \mathrm{~s}$. As such, by using only younger models, advertisers are neglecting a significant consumer segment, especially considering the size and disposable income of the Baby Boom cohort. 
Szmigin and Carrigan (2000) encourage advertisers to "break new ground" by using older models rather than "playing it safe" (p. 233). Clearly, there is evidence to suggest that depicting older models in advertisements can be a successful marketing strategy, enabling firms to differentiate themselves from competitors who continue to use only younger age models. Moreover, as high profile abuses in advertising garner greater attention - whether it is related to shock advertising, sexist messages, racial discrimination, or ageism, the reluctance or sensitivity in ad choices of executives is becoming increasingly questioned and frowned upon by consumer groups (Carrigan \& Szmigin, 2000).

It has been noted that advertising executives are often apprehensive about using older models for fear that younger audiences might be offended; a misperception as older models are not found to actually alienate younger consumer groups. In fact, among a sample of younger age consumers, older models were perceived as more trustworthy and credible than younger models (Steinhaus \& Lapitsky, 1986). Previous authors suggest there is a "...creative challenge of producing sophisticated, innovative well researched, unpatronising advertising campaigns featuring and targeting older consumers" (Carrigan \& Szmigin, 2000, p. 48). Nonetheless, one consistent finding on this topic is prevalent, which is, older consumers seem to prefer models that they can identify with, and indicate strong purchase intention of goods and brands which portray older adults in an attractive, realistic, and positive manner.

\section{Limitations}

Although an attempt was made to collect data from a wide distribution of adult female consumers varying in age and located in two ethnically diverse regions of the United States, ultimately a larger proportion of the sample existed among those 50 and older as compared to those in their 30s and 40s. Additionally, the majority of the sample largely represented one ethnic group. To further explore the relationships among the variables included in this study, additional data should be collected from women of the Generation X era and from more diverse samples of women representing various ethnic and income groups. This research will assist in understanding younger consumers' perceptions of older fashion models, including the relationship between age of the model and younger consumers' purchase intentions and attitudes toward the ad.

\section{References}

Agins, T. (2007, November 5). The boomer balancing act. Wall Street Journal. [Online] Available: http://online.wsj.com/article/SB119403698280880824.html

American boomers now a $\$ 2$ trillion market. (2006, September 28). CNBC. [Online] Available: http://www.msnbc.msn.com/id/12288534/

Americans expect their 'new normal' spending levels to be $86 \%$ of pre-recession levels, according to AlixPartners Poll. (2009, March 30). BusinessWire. [Online] Available: http://www.businesswire.com/news/google/20090329005092/en

Appiah, O. (2001). Black, white, Hispanic, and Asian American adolescents' responses to culturally embedded ads. The Howard Journal of Communications, 12, 29-48.

Berk, C. C. (2009, December 1). Predictions 2010: Consumers. CNBC. [Online] Available: http://www.cnbc.com/id/34124411

Carrigan, M., \& Szmigin, I. (2000). Advertising and older consumers: Image and ageism. Business Ethics: A European Review, 9, 42-50. http://dx.doi.org/10.1111/1467-8608.00168

Chowdhary, U. (2000). Correlates of apparel significance among older men and women. Journal of Consumer Studies and Home Economics, 24, 150-159. http://dx.doi.org/10.1046/j.1365-2737.2000.00116.x

Clayton, R., Lennon, S. J., \& Larkin, J. (1987). Perceived fashionability of a garment as inferred from the age and body type of the wearer. Home Economics Research Journal, 15, 237-246. http://dx.doi.org/10.1177/1077727X8701500404

Coleman-Lochner, L., \& Deprez, E. E. (2010, January 26). Retail sales will advance $2.5 \%$ in 2010, NRF says. Bloomberg. [Online] Available: http://www.bloomberg.com/apps/news?pid=20601103\&sid=azbHv7d.iqKY

Department store sales jump most in 2 years. (2010, December 14). CBSNews. [Online] Available: http://www.cbsnews.com/stories/2010/12/14/business/main7148352.shtml

Festinger, L. (1954). A theory of social comparison processes. Human Relations, 7, 117-140. http://dx.doi.org/10.1177/001872675400700202 
Florin, D., Callen, B., Mullen, S., \& Kropp, J. (2007). Profiting from mega-trends. Journal of Product and Brand Management. 16, 220-225. http://dx.doi.org/10.1108/10610420710763903

Gen X marks the spot for luxury spending. (2006, April 24). AllBusiness. [Online] Available: http://www.allbusiness.com/retail-trade/apparel-accessory-stores-womens-specialty/4239939-1.html

Greco, A. J., Swayne, L. E., \& Johnson, E. B. (1997). Will older models turn off shoppers? International Journal of Advertising, 16, 27-36.

Horyn, C. (2009, September 11). High fashion faces a redefining moment. The New York Times. [Online] Available: http://www.nytimes.com/2009/09/11/style/11 fashion.html

Kavilanz, P. (2010, January 14). A gift for nation's stores: Holiday sales gain. CNN Money. [Online] Available: http://money.cnn.com/2010/01/14/news/economy/holiday_sales_final_result/index.htm

Kim, H. S. (1995). Consumer response toward apparel products in advertisements containing environmental claims (Unpublished doctoral dissertation). Iowa State University, Ames, IA.

Kozar, J. M., \& Damhorst, M. L. (2008). Older women's responses to current fashion models. Journal of Fashion Marketing \& Management, 12, 338-350. http://dx.doi.org/10.1108/13612020810889290

Krathwohl, D. R. (1998). Methods of educational \& social science research (2 ${ }^{\text {nd }}$ ed.). New York: Addison-Wesley Educational Publishers, Inc.

Levinson, D. J. (1996). The seasons of a woman's life. New York: Knoph.

Linn, A. (2008, April 25), Clothing store feel sharp economic pinch. MSNBC. [Online] Available: http://www.msnbc.msn.com/id/24261490/

Moin, D. (2008, December 29). A holiday to forget: Retailers experience aftershocks. Women's Wear Daily. [Online]

Available:

http://www.wwd.com/retail-news/trends-analysis/a-holiday-to-forget-aftershocks-roll-on-from-a-dismal-season1905098? full=true

O’Donnell, J., Petrecca, L., \& Butrymowicz, S. (2008, September 12). Clothing stores rediscover Boomers. USA Today. [Online] Available: http://www.usatoday.com/money/industries/retail/2008-09-11-fashion-boomer-women-talbots_N.htm

Petroshius, S. M., \& Crocker, K. E. (1989). An empirical analysis of spokesperson characteristics on advertisement and product evaluations. Journal of the Academy of Marketing Science, 17, 217-225. http://dx.doi.org/10.1007/BF02729813

Posavec, S. S., \& Posavec, H. D. (2002). Predictors of women's concern with body weight: The roles of perceived self-media and ideal discrepancies and self-esteem. Eating Disorders, 10, 153-160. http://dx.doi.org/10.1002/erv.462

RAB instant background report for Generation X market. (2005, January 27). RAB Instant Background Report. [Online] Available: http://www.rab.com/sales_meetings/GenX.pdf

Retail sales fall, smacking stocks, denting recovery hopes. (2009, May 19). USA Today. [Online] Available: http://www.usatoday.com/money/economy/2009-05-13-retailsales_N.htm?POE=click-refer

Rohan, V. (2009, November 16). Baby boomers older than 50 can still be fashionably fabulous. NorthJersey.com. [Online] Available: http://www.northjersey.com/columnists/70254172.html?page=all

Rosenbloom, S. (2009, January 8). After weak holiday sales, retailers prepare for even worse. The New York Times. [Online] Available: http://www.nytimes.com/2009/01/09/business/economy/09shop.html

Simcock, P., \& Sudbury, L. (2006). The invisible majority? Older models in UK television advertising. International Journal of Advertising, 25, 87-106.

Simons, H. W., Berkowitz, N., \& Moyer, R. J. (1970). Similarity, credibility and attitude change. Psychologcial Bulletin, 73, 1-16. http://dx.doi.org/10.1037/h0028429

Steinhaus, N. H., \& Lapitsky, M. (1986). Fashion model's age as an influence on consumers' attitudes and purchase intent. Home Economics Research Journal, 14, 294-305. http://dx.doi.org/10.1177/1077727X8601400303

Szmigin, I., \& Carrigan, M. (2000). Does advertising in the UK need older models? The Journal of Product and Brand Management, 9, 128-141. http://dx.doi.org/10.1108/10610420010322170 
Timberlake, C. (2010, Dec. 28). U.S. retailers' holiday sales jump 5.5\% on apparel. Bloomberg. [Online] Available:

http:/www.bloomberg.com/news/2010-12-27/u-s-retailers-holiday-sales-jump-5-5-most-since-2005-researcher-s ays.html

Whittler, T. E. (1989). Viewers' processing of actor's race and message claims in advertising stimuli. Generations, 25, 5-9.

Worth Global Style Network [WGSN]. (2007). Think tank: Consumer attitudes - ageless. [Online] Available: http://www.wgsn-edu.com/members/think-tank/features/

Table 1. Age distribution of participants

\begin{tabular}{|c|c|c|c|}
\hline Age Range & Frequency & Percent & Cumulative Percent \\
\hline $30-39$ & 47 & 13.09 & 13.09 \\
\hline $40-49$ & 54 & 15.04 & 28.13 \\
\hline $50-59$ & 84 & 23.40 & 51.53 \\
\hline $60-69$ & 70 & 19.50 & 71.03 \\
\hline $70-80$ & 104 & 28.97 & 100.0 \\
\hline
\end{tabular}

Table 2. Perceived age differences among stimulus models

\begin{tabular}{|l|c|}
\hline & Perceived Age Range \\
\hline Model 1 & $50-59$ \\
\hline Older Version & $30-39$ \\
\hline Younger Version & \\
\hline Model 2 & $60-69$ \\
\hline Older Version & $40-49$ \\
\hline Younger Version & \\
\hline Model 3 & $50-59$ \\
\hline Older Version & $30-39$ \\
\hline Younger Version & \\
\hline Model 4 & $50-59$ \\
\hline Older Version & $30-39$ \\
\hline Younger Version & \\
\hline
\end{tabular}

